\title{
Effect of Interface Friction on Passive Force on Bridge Abutments
}

\author{
Kyle Rollins ${ }^{1, *}$, Amy Fredrickson ${ }^{2}$, and Eric $\mathrm{Scott}^{3}$ \\ ${ }^{1}$ Civil \& Environ. Engrg. Dept., Brigham Young University, 430 EB, Provo, UT 84602, USA \\ ${ }^{2}$ AECOM, 756 E. Winchester St \#400, Salt Lake City, UT 84107 USA \\ ${ }^{3}$ CKR Engineers, 1295 N State St., Orem, UT 84057 USA
}

\begin{abstract}
A correct understanding of passive force-deflection response is important for lateral load evaluations of bridges during extreme events such as earthquakes and from thermal expansion and contraction of the superstructure. In these cases, the ultimate passive force is highly sensitive to the interface friction between the abutment wall and the adjacent geomaterials. These geomaterials may simply consist of compacted sand or gravel; however, for geosynthetic reinforced soil (GRS) backfill a geosynthetic fabric may be placed between the abutment wall and soil which can reduce the interface friction. In still other cases, a zone of compressible material such as geofoam may be used as a barrier between the soil and abutment to reduce lateral earth pressures. To evaluate the effect of the interface friction on passive force-deflection curves, large-scale testing was performed with a test abutment that was $3.35 \mathrm{~m}$ wide and $1.68 \mathrm{~m}$ high. Backfill materials consisted of sand, gravel, GRS backfill, and a geofoam inclusion between a sand backfill and the abutment. As a result of lower interface friction, the GRS backfills only developed $80 \%$ of the force developed by the unreinforced gravel. The geofoam inclusion decreased the passive force by about $70 \%$ as a result of reduced interface friction.
\end{abstract}

\section{Introduction}

A correct assessment of passive force-deflection response is important for lateral load evaluations of bridges during extreme events such as earthquakes and from thermal expansion and contraction of the superstructure. Passive force behaviour is particularly important for seismic e (valuations of bridges because nonlinear plastic deformation of the soil backfill is vital to dissipation of earthquake energy in the abutments [1] 2006).

The magnitude of passive force is highly sensitive to the interface (wall) friction angle $(\delta)$ between the abutment wall and the adjacent backfill. For example, $\mathrm{K}_{\mathrm{p}}$ values of 3 to 4 are typically obtained when wall friction is assumed to be zero as in the Rankine theory, but can be between 10 and 20 when reasonable wall friction values are used ( $\delta=0.6$ to 0.8 times the backfill friction angle, $\phi)$ in the log-spiral theory. Incorrect assessment can significantly alter the computed stress, strain and displacement of the superstructure [1]. A number of large-scale passive force tests have found that the logspiral approach generally provides the best agreement with measured passive force $[2,3,4]$.

Although a proper assessment of interface friction is relatively straightforward for granular backfills such as sand or gravel; little guidance is available for other geomaterial backfills. For example, large scale test data has not been available for Geosynthetically Reinforced Earth (GRS) backfills or backfills where expanded polystyrene blocks (Geofoam) is placed as an inclusion between the concrete abutment wall and the compacted sand backfill behind it. This paper reports results from large-scale field tests with these two backfill types and compares their performance relative to companion tests with conventional backfill materials. In addition, comparisons are provided between measured passive force and that computed using various methods and interface friction gles to determine the most reasonable approach.

\section{Test layouts and backfill properties}

To evaluate the influence of the geotextile and geofoam interfaces between the concrete wall and the adjacent backfill, companion tests were performed. For example, passive force tests were performed on a gravel backfill with and withoutout geotextile sheets between each layer. Similarly, tests were performed on a compacted sand backfill with and without geofoam blocks between the wall and the sand backfill.

\subsection{GRS backfill test layout}

Fig. 1 shows plan and profile drawings of the GRS backfill, the pile cap (used to simulate bridge abutment), and the loading system used to apply lateral force to the backfill. The pile cap consists of a reinforced concrete block $3.35-\mathrm{m}$ wide, $1.68 \mathrm{~m}$ high, and $4.57 \mathrm{~m}$ long. The pile cap was supported by six $32.4 \mathrm{~cm}$ OD steel pile piles filled with concrete. The piles extend to a depth of

* Corresponding author: rollinsk@byu.edu 
approximately $12 \mathrm{~m}$ below the ground surface and ensure that the pile cap does not move vertically. Load was applied using two MTS hydraulic actuators capable of applying a horizontal force of $5300 \mathrm{kN}$ in compression.
The reaction for the actuators was provided by two 1.22$\mathrm{m}$ diameter drilled shaft along with a 9.1-m deep sheet pile wall tied together by two deep beams as shown in Fig. 1.
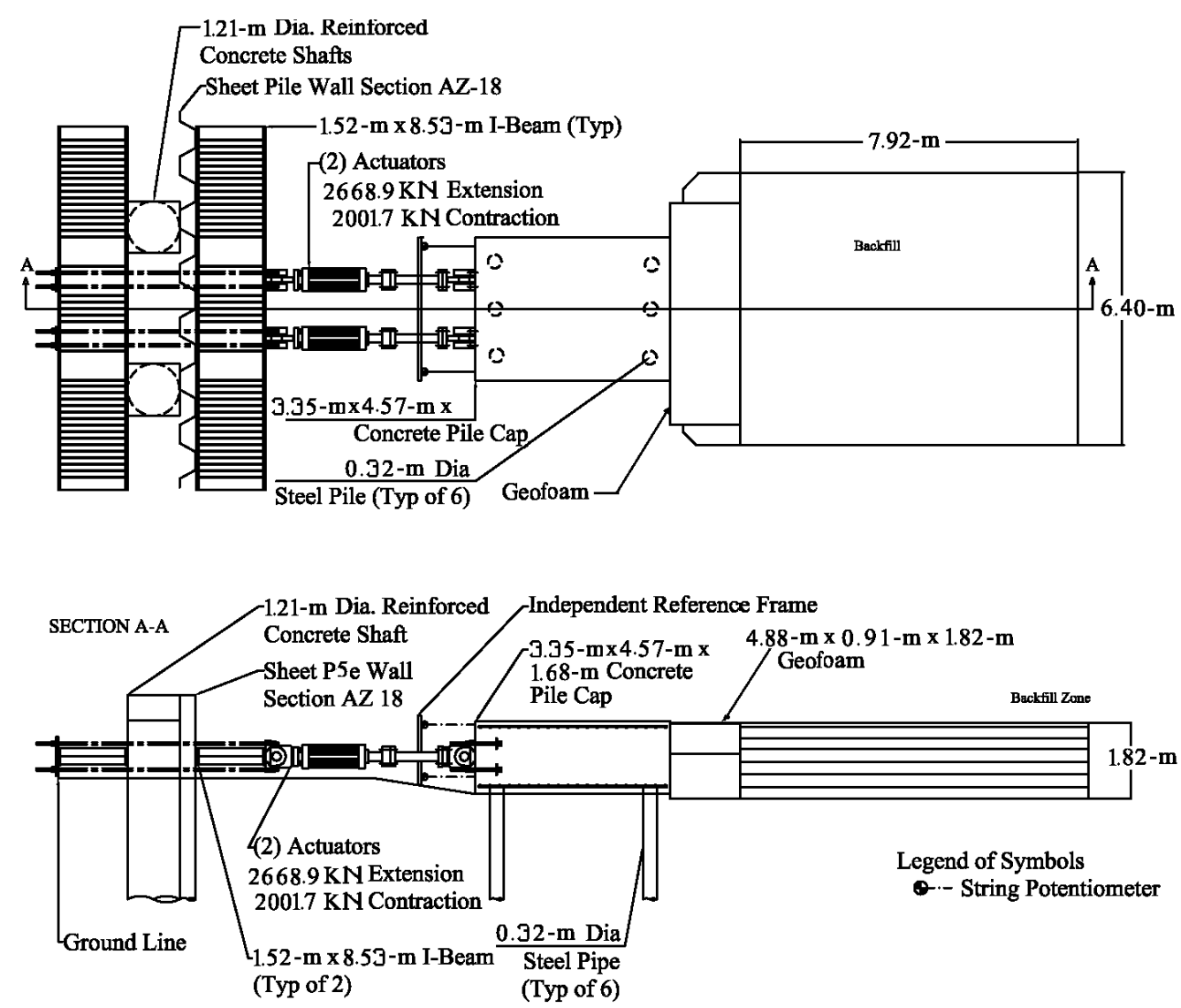

Fig. 1. Plan and profile views of the backill, simulated bridge abutment (pile cap), and loading system for GRS and gravel backfill tests.

The backfill was placed in a test pit that extended a little over $1.5 \mathrm{~m}$ beyond the sides of the pile cap to the edge of the test pit with transverse concrete wingwalls to allow for the development of a 3D failure geometry. The backfill height was $1.07 \mathrm{~m}$ above the base of the concrete wall and extended $30 \mathrm{~cm}$ below the base to fully contain a potential log-spiral type failure surface.

Backfill material consisted of a well-graded gravel with silt and sand (GW-GM according to the Unified Soil Classification System or A-1-a according to the AASHTO classification system). Maximum dry unit weight according to the modified Proctor compaction test (ASTM D1557) was $22.3 \mathrm{kN} / \mathrm{m}^{3}$ and the optimum moisture content was $6.3 \%$. Backfill gravel was placed in lifts approximately $15-\mathrm{cm}$ thick and compacted with a smooth-drum vibratory roller and a walk-behind vibratory plate compactor to an average density greater than $95 \%$ of the modified Proctor maximum. Average dry unit weight was about $21.4 \mathrm{kN} / \mathrm{m}^{3}$ with a moisture content of about $6.6 \%$

The geotextile sheet used for the GRS tests was Mirafi ${ }^{\circledR}$ RS380i which was donated by Tencate Geosynthetics Americas for this research. This geotextile is woven from polypropylene (PP) filaments to provide desired strength and soil retention characteristics along with high water flow capacity. Based on test results from the manufacturer, the geotextile has a minimum tensile modulus of $744 \mathrm{kN} / \mathrm{m}$, which equates to a tensile strength of $37 \mathrm{kN} / \mathrm{m}$ at a strain of $5 \%$.

For the GRS test, the geotextile fabric layers were placed every $0.30 \mathrm{~m}$ starting at $0.15 \mathrm{~m}$ below the base of the cap. The fabric was laid flat so that the extra fabric on the sides and against the concrete wall came up vertically. The fill was then placed on top of the geofabric sheets and compacted. After compaction, at each 0.30-m interval, the fabric against the concrete wall from the previous layer was wrapped over the fill before placing the new layer of fabric. The fabric was placed such that there was at least $0.9 \mathrm{~m}$ of fabric laying on top of the gravel before the next layer was placed. Therefore, the resulting interface between the backfill and the pile cap wall was completely geotextile fabric.

\subsection{Geofoam backfill test layout}

Figure 2 provides plan and profile drawings showing the layout geofoam backfill passive force tests. The pile cap and loading system are identical to that described 
previously. The backfill zone used for both the tests with and without the geofoam inclusion was approximately 6.4 $\mathrm{m}$ wide and $7.9 \mathrm{~m}$ long. The backfill was compacted to a height of $1.68 \mathrm{~m}$ above the base of the pile directly north of the pile cap and geofoam inclusions. To fully contain a potential log-spiral type failure surface, the soil backfill extended $30 \mathrm{~cm}$ below the base of the pile pile cap. Nuclear density tests were performed on each lift to confirm compliance with moisture and density standards.

The backfill was poorly graded sand and classified as SP soil according to the Unified Soil Classification System. The maximum density of the soil according to the modified Proctor compaction test (ASTM D1557) was $17.5 \mathrm{kN} / \mathrm{m}^{3}$ with an optimum moisture content of $7.1 \%$. Average relative compaction was approximately $96 \%$.
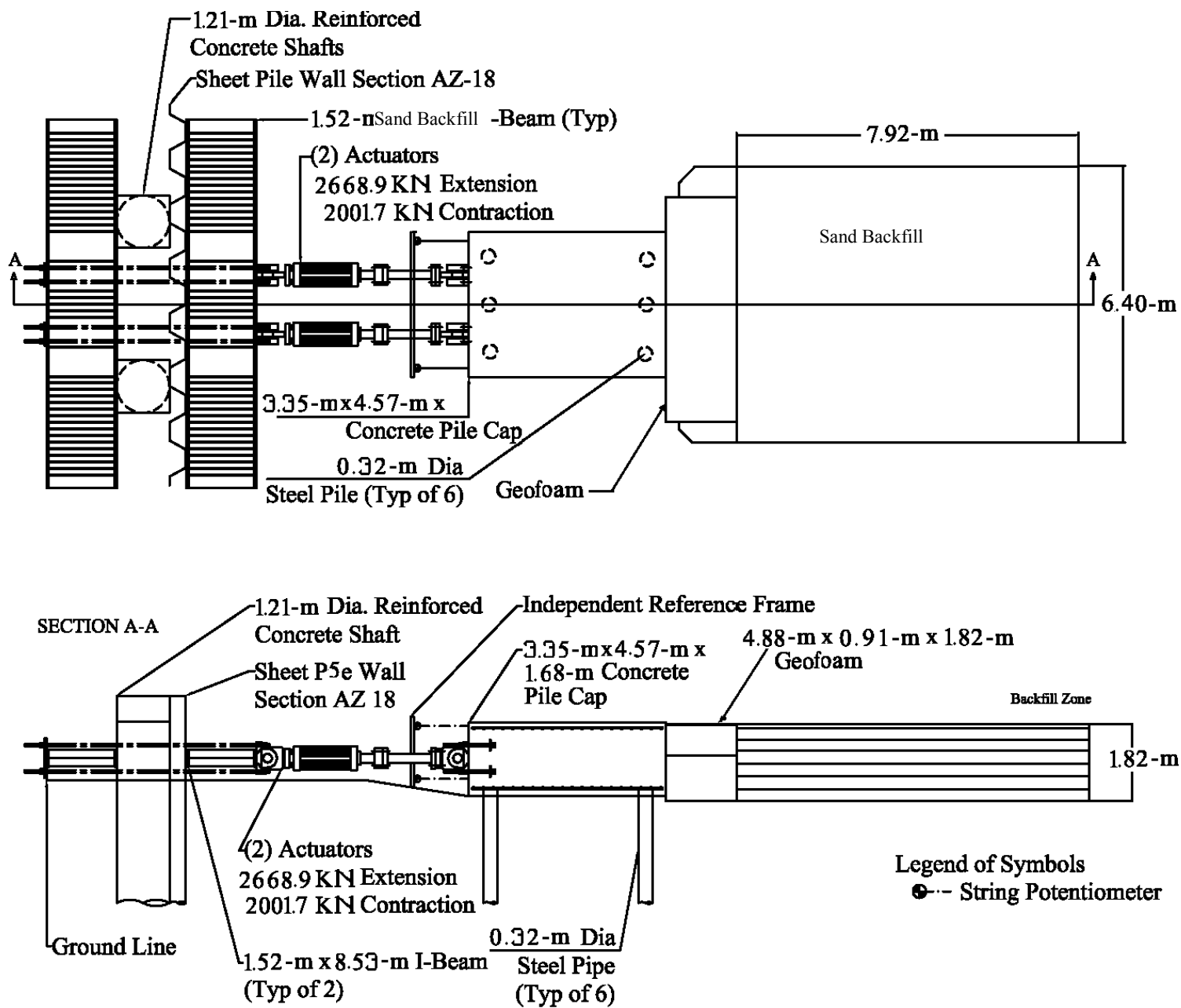

Fig. 2. Plan and profile views of the backfill, simulated bridge abutment (pile cap), and loading system for Geofoam-sand backfill tests.

The geofoam barrier placed between the pile cap and the sand backfill consisted of four blocks of expanded polystyrene (EPS). The bottom two blocks were $1.2 \mathrm{~m}$ tall while the upper blocks were $0.6 \mathrm{~m}$ tall as shown in Fig. 2. These dimensions allowed the geofoam inclusion to extend beneath the pile cap while the top surface of the geofoam remained relatively level with the top of the pile cap. All blocks were $0.9 \mathrm{~m}$ thick in the direction of loading, and $2.44 \mathrm{~m}$ long. Thus, the blocks spanned 4.88 $\mathrm{m}$ at the face of the backfill zone with a joint in the center of the cap.

The geofoam blocks were designated EPS19 which is a medium density geofoam that provides some strength but is also readily compressible when loaded. Geofoam density typically ranges from 12 to $46 \mathrm{~kg} / \mathrm{m}^{3}$ [5]. The " 19 " indicates that the geofoam has a density of $19 \mathrm{~kg} / \mathrm{m}^{3}$ or about $1 / 90^{\text {th }}$ of the dry unit weight of the backfill sand. The elastic modulus of the EPS19 geofoam is $4000 \mathrm{kPa}$. These geofoam blocks offer $90 \mathrm{kPa}$ of compressive resistance at $5 \%$ deformation or $110 \mathrm{kPa}$ at $10 \%$ deformation [6]. The blocks were simply stacked on top of each other and not connected using any mechanical or geometric interlocking system.

\section{Passive force test results}

Passive force test results provided passive force vs. pile cap deflection curves for backfills with and without a geosynthetic interface. The passive force was the sum of the two hydraulic actuators with backfill in place minus the lateral resistance of the pile cap without backfill. Latera load tests were performed without backfill to 
define the lateral force-deflection relationship for this case. The pile cap deflection was the average of four string pots located near the four corners of the back wall face attached to an independent reference frame. Tests were performed using a deflection control approach to obtain points at approximately $12.5 \mathrm{~mm}$ intervals.

\subsection{GRS backfill test results}

Fig. 3 provides a plot of the passive force vs. deflection curves for the GRS backfill and the companion gravel backfill test. Both curves exhibit a hyperbolic curve shape that flattens considerably with deflection. However, even at pile cap deflections equal to $7 \%$ of the wall height, the curves are still increasing slightly. Similar passive forcedeflection curves were reported for a gravel backfill by Rollins et al. [4].

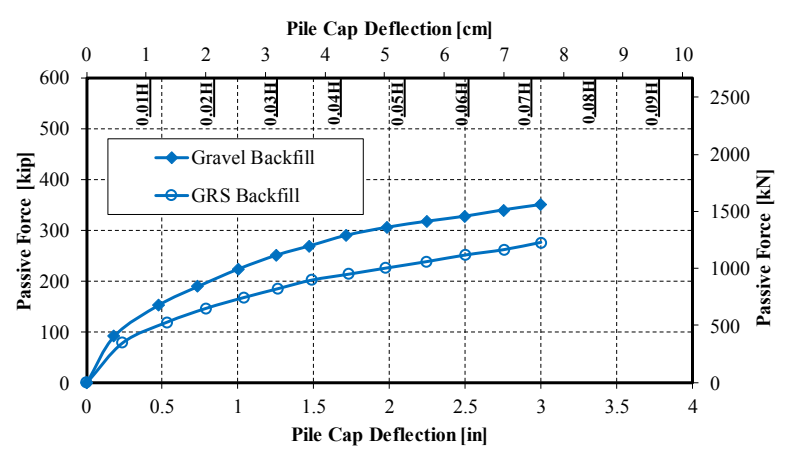

Fig. 3. Passive force vs. pile cap deflection for tests with GRS and companion gravel backfills.

Initially, the GRS backfill was expected to produce higher passive force than the companion gravel backfill without reinforcement because the failure plane would have to develop by passing through each textile sheet. However, the test results actually show a reduction in both stiffness and strength. The reduction in passive force owing to the GRS backfill compared to gravel backfill was $21 \%$ at 7.6 $\mathrm{cm}$ deflection. Apparently, the reduction in interface friction angle for the GRS backfill had a more detrimental effect on strength than the beneficial effect from the reinforcement in the backfill.

Significantly, the decrease in stiffness in the GRS backfill required higher deflections to reach equivalent passive resistances compared to the unreinforced gravel. Although higher stiffness is often desirable, this reduction in backfill stiffness can be favorable in the GRS-IBS abutment configuration because it allows thermal movement without developing excessive induced stresses in the bridge superstructure.

\subsection{Geofoam backfill test results}

Fig. 4 provides plots of the passive force vs. deflection curves for the geofoam inclusion test and for the companion sand backfill test. The peak passive force without an inclusion is $2130 \mathrm{kN}$ and occurs at a pile cap deflection of $5.7 \mathrm{~cm}$ which is about $3.4 \%$ of the cap height. This is in good agreement with previously large- scale passive force tests in which the peak developed with displacements equal to 3 to $5 \%$ of the wall height [8].

In contrast, the passive force vs. displacement curve with the inclusion does not reach a distinct peak but tends to increase very gradually with displacement. At a displacement equal to $3.4 \%$ of the cap height, the passive force with the inclusion is only about $570 \mathrm{kN}$ which represents a reduction in resistance of $73 \%$. Even at a displacement equal to about $9 \%$ of the cap height, the passive force of $800 \mathrm{kN}$ is still about $63 \%$ lower than the peak resistance without the inclusion. Clearly, the inclusion significantly reduced passive force.

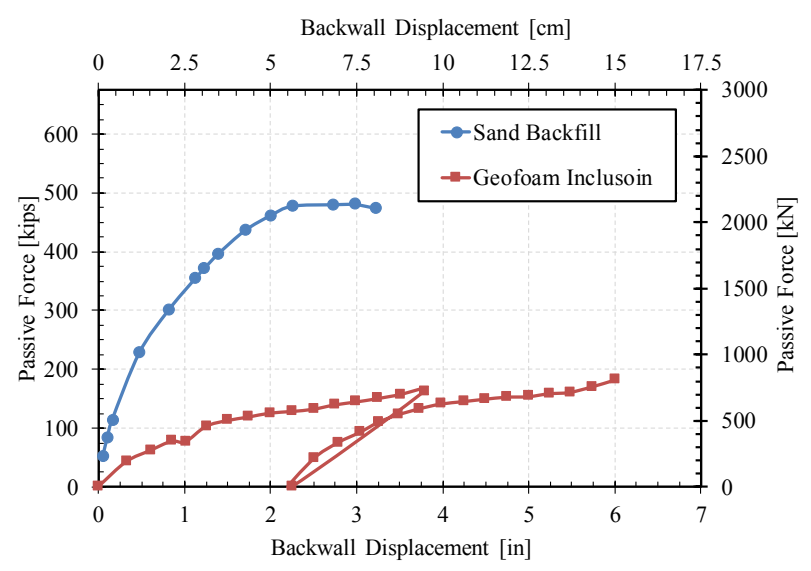

Fig. 4. Passive force vs. pile cap deflection for tests with Geofoam inclusion and companion sand backfills.

Prior to the passive force tests, small auger holes $(7 \mathrm{~cm})$ were drilled through the brown sand backfill and red sand backfill was compacted in the holes. After testing, a trench was excavated adjacent to the holes to determine where the shear plane had offset the red sand columns. This investigation found that the shear plane behind the geofoam inclusion was essentially linear as would be expected for a Rankine failure plane with no wall frction. In contrast, the shear planes within the sand backfill without inclusions exhibited a log-spiral shape which is typical of a granular backfill with wall friction. These contrasting failure geometries suggest that a reduction in the interface friction angle on the wall is likely responsible for the reduced passive force with the inclusion; however,the compressibility of geofoam may play a role as well.

\section{Analysis of passive force test results}

\subsection{GRS backfill test analysis}

To define the strength parameters, in-situ direct shear tests were performed with a $46 \mathrm{~cm}$ square box that was carved into the fill. The friction angle $(\phi)$ was found to be $45.8^{\circ}$. A $3 \mathrm{D}$ correction factor [8] was used to account for shear planes that extended beyond the edge of the cap and increased the effective width. Good agreement with the measured peak passive force was obtained using the log spiral method with an interface wall friction angle $(\delta)$ of $30.2^{\circ}$ for the gravel backfill tests. This yields a $(\delta / \phi)$ ratio 
of 0.66 that is within the typical range $(0.6$ to 0.75$)$ for design [3].

When these same parameters are used to analyze the passive resistance for the GRS backfill, the peak passive force is overestimated by about $20 \%$. The reduced lateral resistance is likely attributable to a reduction in the wall friction caused by the presence of the geosynthetic sheet between the gravel and the pile cap wall. Laboratory interface friction tests between the geosynthetic sheet and the concrete face indicate an interface friction angle, $(\delta)$ of $26^{\circ}(\delta / \phi=0.56)$. This wall friction produced a passive force in good agreement with the measured force. Additional information on testing and analysis is provided elsewhere [9].

\subsection{Geofoam backfill test analysis}

Good agreement with the measured passive force for the sand backfill was obtained using the log-spiral method with $\phi=38.5^{\circ}$ and $\delta / \phi=0.70$. The effective width of the cap was $5.64 \mathrm{~m}$ using the method described in [8]. Using this same friction angle, agreement with measured passive force was only possible using a wall friction $(\delta)$ of zero as assumed by the Rnakine method. Based on the failure surface geometry and the reduced passive force, it appears that the presence of the geofoam inclusion reduces the effective interface friction to a value close to zero. Additional information on testing and analysis is provided elsewhere [10].

\section{Conclusions}

Passive force is highly dependent on the interface (wall) friction. Large-scale tests demonstrate that both Geosynthetically Reinforced Soil (GRS) and Geofoam inclusions reduce the interface friction relative to that of granular soil against concrete, thereby decreasing the passive force. For the GRS backfill the geotextile sheet between the wall and soil reduced wall friction from $30.2^{\circ}$ to $26^{\circ}$ which reduced the passive force by about $30 \%$. The Geofoam inclusion reduced the effective wall friction from $27^{\circ}$ to about $0^{\circ}$ and decreased passive force by about $70 \%$. Failure to account for this effect can lead to significant and unconservative overestimes of both stiffness and peak resistance. The log-spiral approach, with appropriate consideration of interface friction, provided reasonable estimates of the measured passive force.

\section{References}

1. A. Shamsabadi, M. Kapuskar, A. Zand, ThreeDimensional Nonlinear Finite-Element SoilAbutment Structure Interaction Model for Skewed Bridges, 5th National Seismic Conference on Bridges and Highways, FHWA, 1-10.M (2006)

2. K. M. Rollins, R. T. Cole, R. T., J. Geotech. Geoenv. Eng., ASCE, 132, 9, 1143-1153 (2006)
3. J. M. Duncan, R. L. Mokwa, J. Geotech. Geoenv. Eng., ASCE, 127, 3, 248-257 (2001)

4. K. M. Rollins, A. E. Sparks, J. Geotech. Geoenv. Eng., ASCE, 128, 9, 711-723 (2002)

5. J. S. Horvath, Geotext. and Geomemb., 15, 1, 77-120 (1997)

6. EPS Geofoam. "Type EPS19 TechData." $<$ http://www.geofoam.com/technical/>. (6/25/2015, (2015)

7. R. T. Cole, K. M. Rollins, J. Geotech. Geoenv. Eng., 132, 9, 1154-1164 (2006)

8. J. Brinch-Hansen, Resistance of a rectangular anchor slab.” Bull. No. 21, Danish Geotechnical Institute, Copenhagen, 12-13 (1966)

9. K. M. Rollins, E. Scott, A. Marsh, Geofoam Inclusions for Reducing Passive Force on Bridge Abutments Based on Large-Scale Tests.” Procs. Geotechnical Frontiers, Geotechnical Special Publication 279, 5968 (2017)

10. A. Fredrickson, K. M. Rollins, J. Nicks, Passive Force-Deflection Behavior of Geosynthetically Reinforced Soil (GRS) Backfill Based on LargeScale Tests. Procs. Geotechnical Frontiers, Geotechnical Special Publication 278, 23-32, (2017) 